\title{
La hermenéutica cultural como herramienta estratégica de la investigación para el diseño
}

\author{
Miguel Ángel Rubio Toledo1 \\ Arturo Santamaría Ortega ${ }^{2}$ \\ Mayra Guadalupe Herrera Campos ${ }^{3}$ \\ Universidad Autónoma del Estado de México. México
}

RECIBIDO: 16.11.2016 / ACEPTADO: 29.01.2017

\begin{abstract}
Resumen
Históricamente, la hermenéutica ha permitido conocer formas de apropiación de mundos de vida y realidades diversas, hoy su uso se ha ampliado hacia áreas relacionadas con el lenguaje y la cultura. La hermenéutica permite al diseñador desde la investigación estudiar no sólo el lenguaje que puede y debe generar, sino a través de ciertas estrategias y dispositivos de esta disciplina, conocer de manera más profunda al consumidor o cliente al que se le realiza el diseño, con el objeto de que el objeto diseñado establezca un vínculo identitario entre este objeto con su sujeto.
\end{abstract}

Palabras clave: hermenéutica cultural, Herramienta estratégica, Investigación para el diseño.

Cultural Hermeneutics as a strategic tool for Design research

\footnotetext{
${ }^{1}$ Profesor Investigador del Centro de Investigación en Arquitectura y Diseño. Miembro de la Comisión Latinoamericana de Posgrado de la Universidad de Palermo. Director de tesis de más de 50 proyectos de investigación de los Programas Académicos Licenciatura en Diseño Gráfico, Maestría en Diseño y Doctorado en Diseño. Autor de diversas investigaciones, ponencias nacionales e internacionales, artículos indexados, capítulos de libros y libros relacionados con la producción y consumos simbólicos y diseño estratégico. Correo electrónico: miguelblond72@yahoo.com.mx

2 Profesor Investigador del Centro de Investigación en Arquitectura y Diseño. Miembro de la Comisión Latinoamericana de Posgrado de la Universidad de Palermo. Director de tesis de 40 proyectos de investigación de los Programas Académicos Licenciatura en Diseño Industrial y Maestría en Diseño. Presidente del Colegio de Diseñadores Industriales del Estado de México. Autor de diversas investigaciones, artículos indexados, capítulos de libros y ponencias en congresos internacionales relacionados con la sustentabilidad y el diseño estratégico. Correo electrónico: arturo_santamaria@hotmail.com

${ }^{3}$ Ex becaria CONACYT. Artista con más de 50 exposiciones colectivas e individuales en México e Italia. Profesora de diversos cursos y talleres del Consejo Queretano de Cultura, así como en la organización y jurado en diversos eventos y concursos culturales y artísticos. Autora de diversas publicaciones en revistas, capítulos de libros y ponencias en congresos internacionales relacionados con la gestión estratégica del diseño de productos, así como sobre gestión cultural. Correo electrónico: maya.herrera76@hotmail.com
} 


\begin{abstract}
Historically, hermeneutics has revealed procedures of appropriation of life worlds and different realities, today its use has been expanded into related areas language and culture. Hermeneutics allows designers to study not only the language that can and should generate, but through certain strategies and devices of this discipline, meet deepest consumer or customer to whom the design is created in order to establish a link between this object designed with the subject in an identity approach.
\end{abstract}

Keywords: Cultural Hermeneutics, Strategy tool, Design research

\title{
Introducción
}

Desde hace varias décadas, el diseño se ha visto estigmatizado, tanto por profesionales o estudiosos de otras disciplinas o ciencias como por los mismos diseñadores, debido a la falta de fundamentos teóricos que le permitan al diseño consolidarse como disciplina o ciencia. Incluso, se han realizado diversas aproximaciones desde perspectivas científicas de diversa índole con el fin de dar sentido a una teoría del diseño desde la pragmática o experiencia. De manera opuesta otros, en un afán por subsanar esta falta de rigor científico, han caído en un exceso de argumentos ontológicos para teorizar al diseño desde ciencias o disciplinas que les procuran axiomas disciplinarios.

Resulta claro, que dichas posturas -la pragmática y la teoricista- no han logrado definir, en primera instancia, ni argumentar de manera integral su práctica en segunda, posiblemente porque el diseño implica, en su teoría y práctica, partes propias de diversas ciencias, de las artes, y de las tecnologías. La siguiente propuesta empero, sin la intención de pretender dar una respuesta al problema anteriormente descrito en tanto que no su objeto de discusión, sí observa un acercamiento de la teoría a problemas prácticos. Es decir, se trata no de mirar al interior del diseño para su definición última, sino de aportar un fundamento teórico para su operación práctica, esto es, procurar un sentido de mayor cientificidad al diseño, desde la postura hermenéutica cultural.

La perspectiva que se pretende discutir, se funda en un modelo del proceso de diseño básico, en el que existen tres etapas, a saber, investigación, conceptualización y propuesta. Ésta última implica el bocetaje, la selección, la producción virtual u objetual, la implementación y su posible retroalimentación. Sin embargo, esta propuesta trata justamente sobre la primera etapa de investigación que posteriormente da lugar a la conceptualización. Se parte entonces de la premisa de que una investigación profunda del sujeto consumidor, y su contexto otorgan los elementos formales necesarios para el ejercicio intelectual de conceptualizar el objeto de diseño en sus formas necesarias, lo que da lugar al bocetaje posterior. Esta investigación parte entonces de la etnografía como base de la hermenéutica cultural.

El término griego hermeneia significa interpretar y por extensión semántica se observa como traducir o explicar. Para todos los casos se trata de un proceso que busca la comprensión, ya sea hacia el exterior o hacia el interior. La palabra proviene del mitológico Hermes y su misión de transmitir la voluntad de los dioses griegos a los humanos. Asimismo, se entiende también que hermeneia significa tanto el arte o techné del hermeneutés -el que traduce a un lenguaje inteligible lo dicho de un modo que no lo es-. Es decir, la 
acción de explicar o significar algo hablando, en virtud de que el que se expresa traslada pensamientos (Abbagnano 1998).

De tal modo, el sentido actual que tiene el término 'hermenéutica' se relaciona directamente con el de interpretación interpretatio, colindando al de explicación, esto es, penetrar en la intención del texto. Así, se modifica el sentido de manifestar el logos interior mediante el lenguaje, esto es, el intérprete o hermeneuta quiere hacer decir al texto lo que el texto quiere decir, porque una cierta distancia es inherente al mensaje mismo (Lizarazo 2004). Para loa efectos de este trabajo, se trata de una observación y registro profundo, cuyos textos son los mismos consumidores y sus contextos socioculturales.

Aun cuando el arte de interpretar se ha aplicado históricamente a los textos escritos -particularmente a los religiosos-, la filosofía trascendental y la reacción contra el romanticismo, especialmente interesada por el lenguaje, la cultura y el arte, fueron los factores determinantes para el desarrollo de una teoría general (filosófica) de la hermenéutica. Se puede entender que, como filosofía de la acción, la hermenéutica se emparenta con la modernidad. Es decir, no se ocupa sólo del modo de proceder para una interpretación adecuada, sino se cuestiona el hecho mismo de comprender su condición de verdad como posibilidad.

En este sentido, la concepción idealizada de la subjetividad relaciona a la naturaleza de la expresión individual como una equivocación, es unívoca en el sujeto, pero no en el grupo; se traslada de la casuística propia de las hermenéuticas especiales a la de una hermenéutica general. En tal virtud, se entiende que sólo puede surgir esta hermenéutica general cuando resulta seguro que las imágenes del mundo no son simples duplicaciones de la realidad, tal como es, sino que representan interpretaciones vivenciales o experienciales (pragmáticas). Es decir, implícitas en nuestra relación de hablantes con el mundo, aquí se percibe su vínculo con el diseño.

Con este giro lingüístico tramado en la filosofía -en lo particular por la Hermenéutica- y su preocupación metódica, que echan mano del comprender para proporcionar un método a las ciencias del espíritu, se comprende la asimilación filosófica de la hermenéutica. Por tanto, ésta ligada a la necesidad moderna de una teoría del significado en la distinción del lenguaje metafórico como realidad, otorgan condiciones herramentales para proyectar el diseño desde la investigación.

Esta indagatoria profunda y su reconstrucción interpretativa de rasgos culturales de los posibles perceptores de objetos de diseño, desde sus expresiones metafóricas o simbólicas, permiten construir modos y modelos de conceptualización para la propia creación de objetos de diseño identitariamente vinculantes entre objetos y sujetos, formando relaciones simbólicas desde la metáfora. En otras palabras, los rasgos culturales de los sujetos, que son expresados en metáforas, se convierten en rasgos de los objetos de diseño; para ello se utiliza a la hermenéutica cultural como herramienta de investigación. Esta es la propuesta concreta.

\section{Desarrollo temático}

En los últimos años, del siglo XX y los primeros del XXI, se ha modificado la visión de la investigación en las ciencias humanas y sociales, desde una radicalización de la dimensión hermenéutica dentro del 
planteamiento de las ciencias sociales, hasta la profundización del enfoque de la estética de la recepción en la ciencia literaria. En la cotidianeidad, la interpretación ostenta un papel de primer orden en el terreno de la existencia vivida, esto es, pre científica, en la disposición que se le da a la conducta, opiniones, juicios de valor. Se trata entonces de que, en tanto la universalidad de la experiencia hermenéutica y de su eficacia profunda, influyen sobre la conciencia individual como condición del ser -ontológica-, el lenguaje ejerce un papel de mediador entre lo común que se encuentra disponible en alguna forma objetivada o material y la comprensión y apropiación individual.

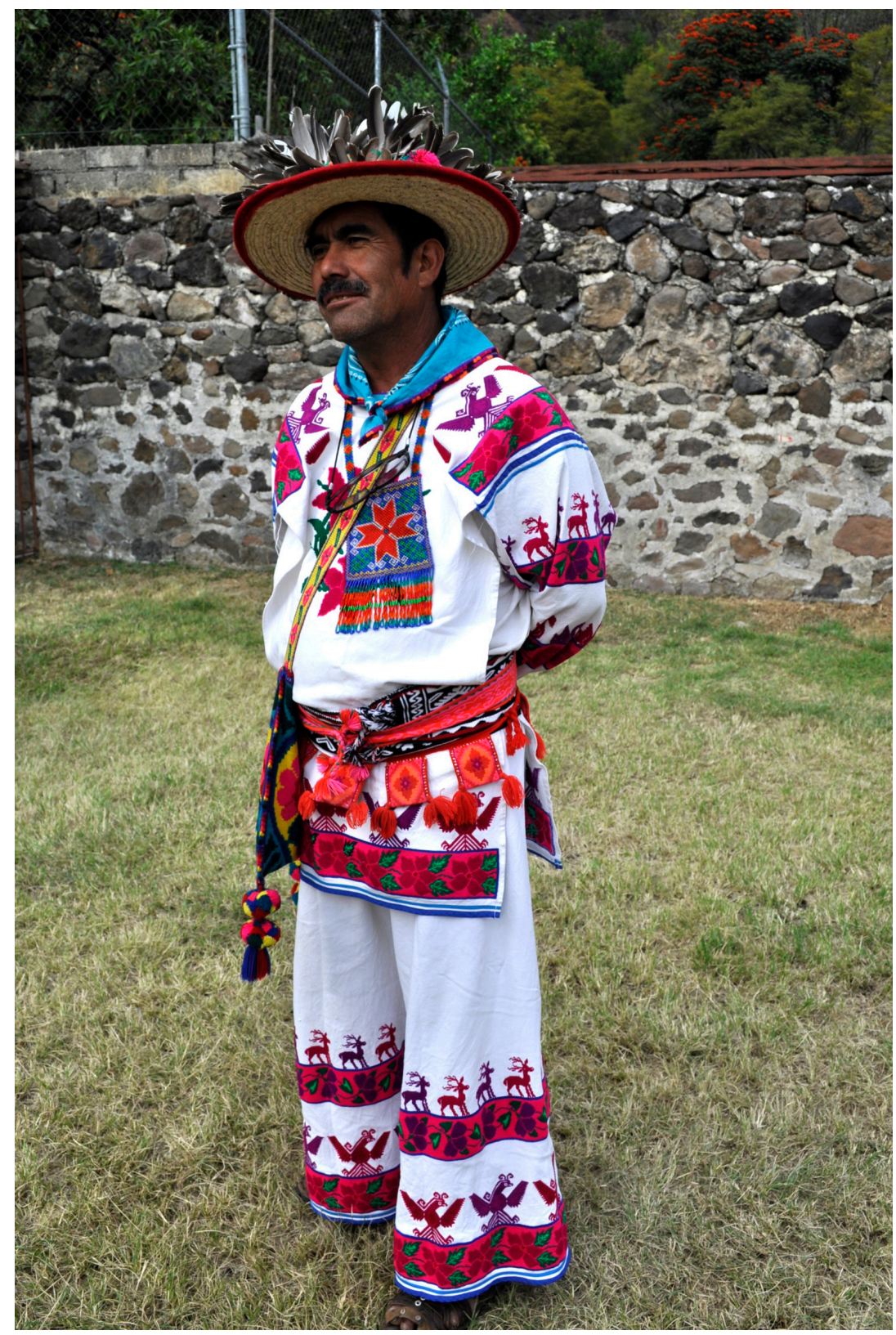

Fig. 1. Representación de la cosmología Huichol en prendas textiles, en las que se pueden observar venados, águilas, y peyotes, entre otros.

Fuente: Mayra Herrera, 2010. 
En este sentido, el lenguaje hace posible la historia como saberes mediante un diálogo permanente en el que participan sucesivas generaciones (círculo hermenéutico). Es por eso que la comprensión lingüística continúa teniendo una responsabilidad importante en la filosofía hermenéutica, hasta el punto de poder afirmar que la universalidad que encuentra la hermenéutica, aquélla por la que se considera filosófica, es la que corresponde al lenguaje. Es una universalidad que nace de la simbiosis de historia y estructura especulativa, esto es, el lenguaje que da la palabra 'private' a lo dicho en la tradición, constituye el verdadero acontecer hermenéutico, un acontecer que es apropiación e interpretación (Gadamer 1977).

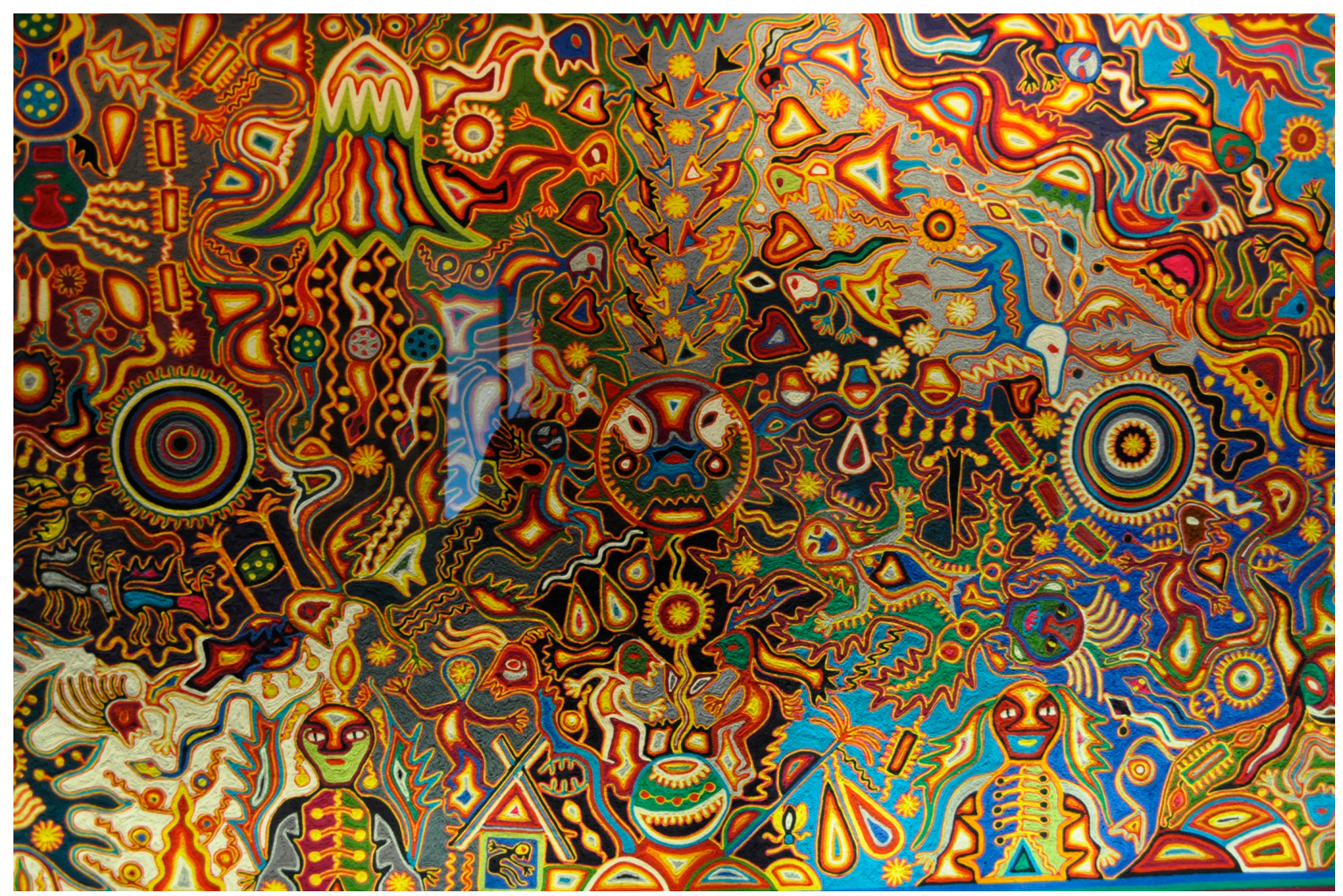

Fig. 2. Otros elementos constitutivos de las creencias religiosas Huicholes en textiles, en el que se puede observar al cielo y al infierno. Fuente: Mayra Herrera, 2010.

Desvelar las metafísicas, a las que se ha entregado la civilización occidental, es lo único que puede llevar la existencia humana a una plena responsabilidad de sí misma, es decir, a una existencia auténtica (Heidegger 2003). Así, Heidegger sigue a Dilthey en cuanto al contenido del término hermenéutica, a saber, entiende que interpretarse a sí mismo y explicarse su mundo forma parte del modo de existir humano como parcela de su identidad asimilada y fragmentada. El hombre no se encuentra en su mundo como un observador neutral, sino que está implicado en todo acontecer y lo interpreta con referencia a significados para su propia existencia, mediada por el lenguaje.

Con la herencia heideggeriana, constituida tanto por las tesis existencialistas como la idea del final y superación de la filosofía, se puede confrontar cualquier propuesta filosófica contemporánea, y cuyas 
últimas consecuencias sugieren la declaración del final de la metafísica. Es decir, el lenguaje ostenta un significado cognitivo y ontológico propio, en la misma medida que es una reproducción de la finitud humana, necesitada de sentido. En plena sintonía con la crisis de la razón, algunos pensadores tan diferentes como Gadamer (1977), Ricoeur (2001), Derrida (2006), o Vattimo (1998), han argumentado la crucial importancia de la narrativa en desvelar saberes generacionales para argumentar y teorizar de manera profunda y significativa, especialmente desde la interpretación.

En términos más relacionados con la temática, de nuestra disciplina de diseño, la hermenéutica como aproximación epistemológica se puede observar bajo dos vertientes complementarias. Por un lado, se trata del análisis de objetos diseñados o creados para otorgarles una posibilidad de interpretación. Es decir, la comprensión o traducción de las claves narrativas que sugiere la poiesis, determinada en tanto objetos diseñados desde su autor. Por otro, y quizás aún más importante para los intereses del diseño, alude a la comprensión de los sujetos -o grupos de ellos- que consumen o perciben dichos objetos, en cuyo estadio de apropiación se pueden percibir los vínculos identitarios que se expresan interna o externamente y que se posibilita su utilización en el desarrollo de objetos como proyectos de diseño, haciendo uso de las formas etnometodológicas de análisis.

En otras palabras, la idea de esta propuesta es utilizar la hermenéutica como herramental teórico metodológico que permita articular los elementos de investigación de referentes empíricos generados a través de características de la cultura particular, con fines de otorgar sentido a la rasgos simbólicos de apropiación de vida de los consumidores o perceptores, expresados no de manera directa sino de manera simbólica y, particularmente, a través de metáforas objetuales y sociales, para efectos de generar objetos de diseño que ostenten vínculos identitarios con dichos consumidores, y del mismo modo a través de discursos metafóricos gráficos, visuales, objetuales o espaciales.

En términos metodológicos una descripción densa, tal y como la describe Geertz (2001) en la antropología cultural, observa el fundamento generado a partir de referentes empíricos obtenidos de aproximaciones etnográficas, principalmente vinculados con los rasgos simbólicos narrativos -verbales y no verbales-. Este autor sostiene que la Antropología cultural debe ser, más que una ciencia experimental en busca de leyes rígidas o duras, una ciencia de interpretaciones en busca de posibles significados profundos. Así, sugiere que lo que se busca es la explicación a través de la interpretación de expresiones sociales que son en apariencia superficiales, pero que llevan en sí el germen de la explicación de esa forma cultural.

Se trata de representaciones simbólicas con sus matices de expresión tales como los modos del lenguaje oral, los cuerpos vestidos y adornados, las formas de danzas o músicas, las manifestaciones faciales con sus coloridas decoraciones, los accesorios de los atuendos, la narrativa particular de la cosmovisión, entre muchas otras, permiten conocer lo que es observado en las conductas sociales a los pertenecientes a una cultura. Geertz sugiere que la cultura no es una entidad en la que pueden atribuirse de manera causal acontecimientos sociales, modos de conducta, instituciones o procesos sociales, sino que se trata de un contexto dentro del cual pueden describirse todos estos fenómenos de manera inteligible o, dicho de otro modo, de manera densa. De este modo, el diseñador en la etapa de investigación requiere realizar 
interpretaciones amplias haciendo análisis más abstractos con base en la abundante información de signos aparentemente pequeños.

Así, Geertz (2001) afirma que el estudio de las culturas debe realizarse mediante la interpretación de las expresiones sociales, es decir, una etnología mediante explicaciones elaboradas o "descripción densa". Ésta implica desentrañar la multiplicidad de estructuras de significación (sentido y valor) a través del lenguaje que dé una explicación (pensamiento, contenido, intención) holística del fenómeno social. Asimismo, y con fines de evitar la noción universal del subjetivismo, este autor en el texto Los usos de la diversidad (1996) supone que debe existir un módico relativismo, esto es, una aceptación de la diversidad cultural existente, dicho de otro modo, desde una perspectiva de integración, las culturas deben -como acto moral- aceptarse para enriquecerse mutuamente.

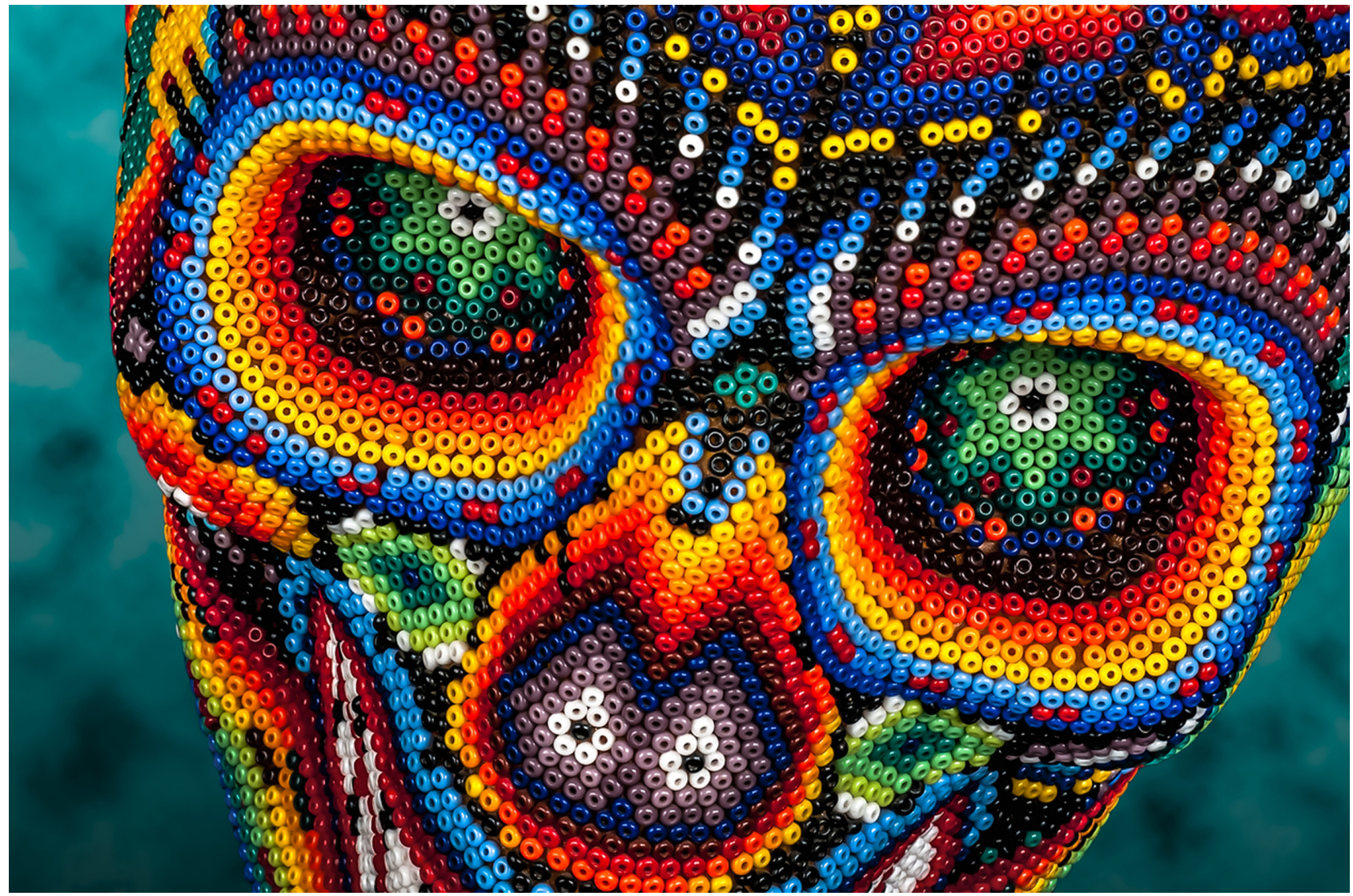

Fig. 3. Calavera Huichol decorada con la técnica de chaquira, que es la base del logotipo de los Juegos Olímpicos de México 1968. Fuente: AGcuesta, 2017, Disponible en línea en: http://www.huffingtonpost.com.mx/2016/09/25/el-arte-huichol-inspira-para-romper-record-guiness/

Además, sostiene que el significado se construye socialmente mediante el lenguaje, el cual requiere acceso imaginativo y admisión de una disposición mental ajena, como un collage cultural, cuya razón debe verse como acto moral y no como acto social ${ }^{4}$. Esta perspectiva antropológica parece fundamental para el

${ }^{4}$ La lógica de las Ciencias Sociales parte no sólo de la lógica racional sino también de la lógica simbólica. 
desarrollo de proyectos de diseño, en tanto las formas culturales metaforizadas tienden a formarse mediante agentes retórico-estéticos susceptibles de ser analizados por medio de los signos que presentan, no únicamente desde el plano visual, sino en el plano de explicaciones elaboradas a partir de los sentidos y valores que le otorgan a sus propios pensamientos, contenidos e intenciones.

Las expresiones sociales son las formas en que los sujetos se relacionan con otros, cuyo lenguaje verbal y no verbal se analiza etnológicamente para conocer la forma y contenido de sus pensamientos, las preocupaciones sobre sus creencias, las intenciones de relación, y los resultados de esta misma. Cabe resaltar que el análisis no es puramente de percepción del lenguaje, lo que puede dar lugar a un relativismo exacerbado, sino como consecuencia de un estudio riguroso en el cual estén inmersas las técnicas propias de la investigación etnológica. Además, una vez que se realiza la investigación extensa, la interpretación de la información debe dar lugar a un sentido amplio de significados no necesariamente racionales, en términos de razón pura, sino de razón moral o simbólica. Es decir, de aceptación y comprensión de la realidad estudiada, explicando su proceder de manera completa o, dicho de otro modo, densa.

Las formas culturales se presentan y representan mediante aspectos simbólicos, susceptibles de ser estudiados mediante sus expresiones metafóricas, cuyas simbologías son figuras simuladas de sus pretensiones ontológicas. En este sentido, se contemplan las significaciones de sus fundamentos simbólicos tales como los ritos que llevan a cabo, además de la historicidad y contextualización del mismo. Lo anterior en el entendido de que la estética expresada no solo implica la presentación y representación sensorial visible de la fruición de las manifestaciones de los diversos grupos -targets o mercadometas para el diseño-, sino que implica el conocimiento de la esfera privada y pública del grupo, esto es, estética en el mismo nivel de conocimiento.

Del mismo modo, se recuperan los mitos que parten de apologías o leyendas sobre los sujetos y objetos que son modelos a seguir, ya sea que aún vivan, que sean personajes ya fallecidos, que convivan con ellos, u objetos de fetiche o culto. Del mismo modo se estudian los vínculos afectivos que comparten, su estructura jerárquica, sus historias de vida, en fin, todo el estudio sociocultural de manera que se llegue a una explicación densa del fenómeno. Es importante resaltar, que estas expresiones culturales son generalmente representaciones metafóricas de tales realidades, por lo que la importancia de una descripción profunda y su pertinente interpretación resultan necesarias.

Por su parte Garfinkel (1967), define la etnometodología como la investigación de las propiedades racionales de expresiones indicativas y otras acciones prácticas como logros progresivos eventuales de prácticas organizadas de la vida diaria. El autor intenta descubrir las propiedades formales comunes, las acciones con sentido común práctico, soslayando la función totalizadora de la deducción analítica, las simulaciones o revisiones de libros, ya que, a decir del propio autor, las investigaciones sociológicas son prácticas completamente, es decir, tiene un carácter empírico fundamentalmente. Así, la importancia radica en lo observable y reportable, información disponible a miembros como prácticas situadas en observación y participación, lo que por añadidura requiere de la observación participativa como técnica fundamental. 
En este sentido, la práctica social en su propio contexto es la única forma de obtención de información legítima. Los hechos sociales son arreglos prácticos de los actores sociales, y en donde la comprensión de la acción se encuentra, es decir, la ética como sistema de valores de conducta precede a la estética también como sistema de valores perceptuales. Así, los actores sociales son los sociólogos mismos, quienes acumulan y decodifican la información, proceso que es fundamental para el diseño en su etapa de investigación y conceptualización.

Los hechos sociales reportables son determinados como procesos. Se pretende entonces, un entendimiento común como un acuerdo compartido, se trata de aceptar los propios códigos para establecer la medida de comunicación. Los reportes científicos implican el uso de la registros como procedimientos a manera de archivo de las vivencias, así como las indagatorias de gente cercana para la reconstrucción de la forma de vida del actor social, es decir, con base en las señales recabadas. Tales señales son, por supuesto, los rasgos metaforizados ya mencionados y que, en su momento, darán la información necesaria para la conceptualización que requiere el diseño para la creación de los objetos con fines identitarios.

Por su parte Clifford (1992) refiere la autoridad etnográfica como modo de operar la legitimidad o incluso la verdad de la práctica social. Dado que los modos occidentales de obtención de información han sido rebasados, la única forma de generación de autoridad científica es mediante invenciones ad hoc, a modo de dispositivos diseñados estratégicamente, la teoría a construirse no es un sistema sino un instrumento, es una lógica de la especificidad de las relaciones de poder y de las luchas alrededor de ellas, la cual sólo puede ser sobrellevada a partir de una reflexión acerca de situaciones determinadas.

Siguiendo a Garfinkel (1967), la técnica de la observación participante obliga a los etnógrafos -o diseñadores según esta propuesta- a experimentar tanto a nivel intelectual como corporal las vicisitudes de la traducción. De este modo, la forma de traducción se determina en la escritura lingüística a nivel de texto, implicando la importancia de la textualidad como cohesión entre las prácticas del diseñador como etnógrafo y del antropólogo volviéndolos uno solo. Aquí surge el problema ya mencionado de la interpretación y la experiencia, esto es, si bien la experiencia da un cierto grado de autoridad a la interpretación aun cuando se lleve de manera sistemática la técnica, siempre queda lugar para un sesgo por mínimo que sea, de manera que la objetividad no lo es de modo total. A decir de Garfinkel, el etnógrafo lee un texto en relación con el contexto, constituyendo entonces otro mundo significativo, cuya comprensión del curso general de la investigación es una negociación continua.

Marcus y Cushman (1991) sugieren que la etnografía observada como una serie de textos de posibilidad de interpretación, dan importancia primordial a la retórica y narrativa del etnógrafo. A decir de los propios autores las prácticas de investigación de la disciplina social son circunscritas fundamentalmente por la interpretación de los textos etnográficos como determinación teorética. En este sentido, se plantea que se le dé particular importancia a una ciencia de la interpretación, de naturaleza hermenéutica, implicando incluso el uso de la creatividad para la construcción de interpretación de textos para los análisis culturales y los proyectos de diseño, es decir, que se le otorgue igual importancia a la interpretación de los textos etnográficos que a la misma expresión objetual de diseño. 
De acuerdo con Ricoeur (2001), todos los sistemas simbólicos contribuyen a configurar la realidad, esto es, la investigación densa a través de la comprensión de los rasgos metaforizados y el diseño mediante la expresión también en metáforas o discursos simbólicos. Cabe resaltar que lo que otorga autoridad (no necesariamente verdad) al diseñador etnógrafo y sentido a la realidad concreta del texto, es la afirmación del escritor de que él representa un mundo como sólo puede hacerlo alguien que lo conoce de primera mano, estableciendo un nexo entre la escritura etnográfica y el trabajo de campo. Por otro lado, lo que revela el análisis retórico es la forma en que el lenguaje y la construcción narrativa de un texto histórico o etnográfico precodifica tanto el objeto de análisis como los fundamentos de una argumentación específica del proyecto.

En este sentido, la importancia de la propuesta se observa de manera práctica en la elaboración de un objeto de diseño -o sistema de objetos-, en el que el diseñador debe ostentar y reconocer diversos tópicos relacionados con la proyección de tal objeto, tales como el tema y sus posibles vertientes disciplinarias, los materiales que se deben considerar, el lugar en el que se deberá colocar, el tipo de personas que lo percibirán, entre otros, con el objeto de lograr los objetivos de diseño previstos con antelación. Es justamente esta última idea donde la hermenéutica cultural es aplicada como herramienta estratégica.

Los diseñadores investigan de manera profunda -o de modo denso- los elementos simbólicos sagrados o religiosos del grupo que consumirá tal cartel, y que incluso estos rasgos pueden parecer los más pequeños o sin importancia, esto es, aquellas características que se refieren a sus creencias profundas, con el objeto de utilizarlos para conceptualizar, como ejercicio intelectual, los dispositivos lingüísticos formales del discurso, a saber, la paleta de colores, el tipo de formas, el estilo, la familia tipográfica, los signos que deberán ser utilizados en el sustrato físico o virtual del objeto de diseño, los cuales se encuentran vinculados con el grupo previamente investigado.

Es necesario advertir que, de acuerdo con Emile Durkheim (1995), lo religioso trata de la representación simbólica a través de manifestaciones rituales y míticas de una realidad observable, similar a la ciencia pero de modo distinto. Esto es, el relato de verdad visible o tangible científico mediante una lógica determinada; sin embargo, lo religioso también es una verdad reproducida en lo social, pero con base en otra lógica, la de la creencia en lo sobrenatural, en la cual se encuentran los seres espirituales o divinos, no necesariamente humanos, o sea fetiches o seres de culto por algún tipo de virtud particular o capacidad de hacer algo fuera de lo normal. Según Durkheim la religión es un todo formado por partes, un sistema complejo de mitos, ritos, dogmas y ceremonias.

Esta descripción densa y su interpretación se convierten en una herramienta que permite crear identidad entre dicho grupo y su objeto diseñado, esto es, la creencia y el signo creados. Se trata del uso simbólico con fines estratégicos del diseño de la identidad y aspectos religiosos, desde una descripción densa como herramienta. Es importante señalar, que existen diferentes ejemplos de este tipo de investigación etnográfica para el diseño, aun cuando se trata de una investigación más ligera y menos profunda, sin un orden científico y sistémico, y son conocidos como etnografía rápida o sucia (quick o dirty ethnography). 
Resulta fundamental entonces escudriñar en los rasgos sagrados del grupo de consumidores probables, como base de la conceptualización del diseño, con el objeto de crear vínculos significativos entre los objetos de diseño creados y el grupo mencionado. Del tal suerte, cuando un grupo de consumidores reconocen - de manera consciente o inconsciente- partes importantes de sus vidas o de sus creencias en el objeto de diseño, el vínculo identitario es logrado. Estas características sagradas son trasladadas al alfabeto visual o de diseño, siendo éstas los colores, formas, ritmos, líneas, dimensiones, escalas, proporciones, texturas, posiciones, entre otros, que se encuentran en tal objeto de diseño, pero siempre respetando las características simbólicas; y es justamente aquí donde se puede observar si el diseño alcanza o no los objetivos propuestos con antelación.

Incluso, las diferentes posibilidades cognitivas de expresión al usar esta herramienta pueden ser estudiadas para determinar la manifestación discursiva de tales expresiones, no obstante, esta idea no es considerada en el objetivo de este artículo. Es importante señalar, que los diseñadores utilizan diversas formas de investigación para conocer a su audiencia, muchas de ellas relacionadas con las áreas de la mercadotecnia; sin embargo, la importancia de esta propuesta radica en la investigación sistemática desde lo simbólico, con el uso de las teorías, métodos y técnicas de la etnografía hermenéutica, que permiten apuntalar esta primera etapa del proceso de diseño, con miras, como se ha señalado repetidamente, a la conceptualización.
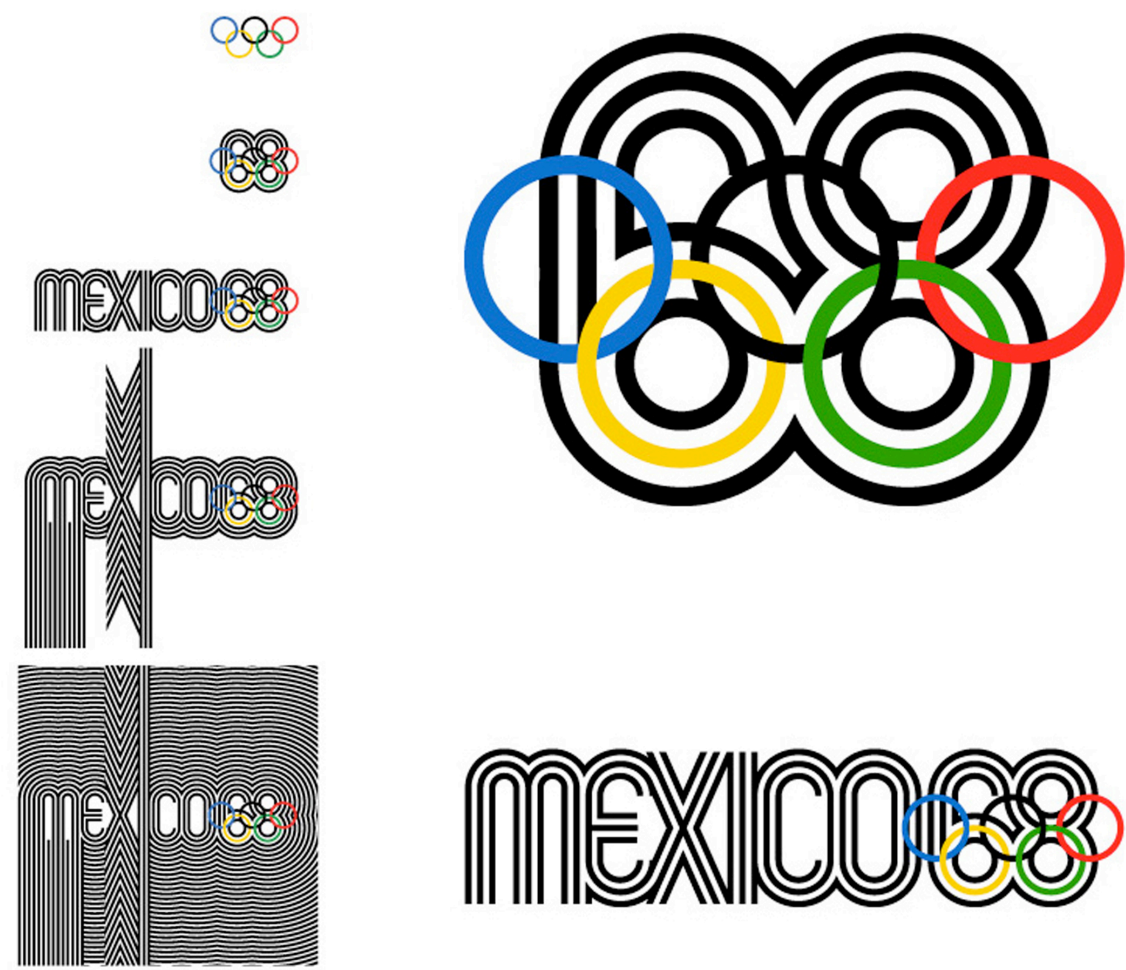

Fig. 4. Logotipo de los Juegos Olímpicos de México celebrados en 1968, donde se observa a relación compositiva del arte Huichol y dicho logotipo. Fuente: Pinterest, 2017, Disponible en línea en: https://es.pinterest.com/pin/13299761374403579/ 


\section{Conclusiones}

La explicación densa a través del estudio de los grupos sociales a partir de sus rasgos culturales permiten conocer de manera profunda las formas simbólicas o sagradas que ostentan los grupos para los que se diseña. Esto es, las formas simbólicas religiosas que mueven a los sujetos permiten establecer vínculos identitarios entre los sujetos consumidores y los objetos diseñados. Se trata de que a partir de la necesidad del proyecto de diseño se puedan revelar a través de estos rasgos culturales los códigos cromáticos, formales o tipográficos que vayan de acuerdo con las creencias de dichos sujetos; el papel del diseñador es traducir estos rasgos mediante los objetos de diseño en estricto sentido de identidad.

Es importante señalar, que de acuerdo con la propuesta hermenéutica, la comprensión en la investigación no tiene un carácter primario (primera impresión de estos rasgos), sino como relación de dichos rasgos en un discurso o serie de textos que son percibidos por los sentidos y cuya estructura es construida en lo social como metáfora de tales rasgos, y posteriormente deconstruida -o expresada- en lenguaje de diseño (planos, líneas, texturas, colores, dimensiones, familias tipográficas, ritmos, texturas, entre otros), generalmente simbólico. Dicho de otro modo, al encontrar las relaciones de causa de las profundas formas culturales y sociales de los grupos o sujetos mediante su interpretación densa o simbólica, se pueden determinar los elementos formales y conceptuales de los objetos de diseño desde la visión del diseñador, estableciendo el vínculo de identidad entre el objeto diseñado y las formas religiosas del grupo, mercado meta, target, público meta, perceptor, consumidor o cualquier otra denominación que exista para este conglomerado demográfico específico.

La hermenéutica en su forma metodológica de descripción densa o etnografía de origen cultural, es una herramienta que permite que el diseñador en su etapa de investigación desarrolle los diversos procesos intelectuales inherentes a la conceptualización del diseño desde la investigación del consumidor o cliente. El diseñador al conocer y comprender las formas simbólicas que se encuentran en el profundo sistema de creencias de aquellos a quienes se diseña, le permite generar conceptos vinculados a la identidad de éstos, para que posteriormente pueda desarrollar objetos de diseño que necesariamente estén relacionados con estos sistemas de creencias. Así, los procesos de diseño adquieren cientificidad en cuanto a su práctica desde la teoría, o sea, la hermenéutica como teoría de la interpretación adquiere una aplicación práctica en el desarrollo de proyectos de diseño.

Del mismo modo, resulta importante mencionar que en el diseño se le otorga una gran importancia a las técnicas de expresión y a las nuevas tecnologías, es decir, la capacidad de dibujar o trazar imágenes, maquetas tridimensionales o tipografías desde computadoras especializadas que ostenten un impacto significativo en cuanto a su discurso formal, lo cual es evidentemente necesario, pero no en mayor medida que la investigación profunda que le otorga sentido e identidad a tales expresiones. Cuando no se realiza una investigación profunda de los posibles consumidores y sus contextos culturales se corre el riesgo de dibujar sólo expresiones preciosistas sin contenido, las cuales pueden resultar agradables a la vista, pero probablemente no cumplan los objetivos de diseño que se plantearon originalmente. 


\section{Bibliografía}

ABBAGNANO, N. Diccionario de filosofía, Martins Fontes, Sao Paulo, Brasil 1998.

CLIFFORD, J. Dilemas de la cultura: antropología, literatura y arte en la perspectiva posmoderna, Gedisa, Barcelona, España 1988.

DERRIDA, J. La deconstrucción en las fronteras de la filosofía, Paidós, Barcelona, España 2002.

DILTHEY, W. Obras, 10 vols. Fondo de Cultura Económica, México 1945.

DURKHEIM, E. Las formas elementales de la vida religiosa, Gedisa, Barcelona, España 1995.

GADAMER, H.G. Verdad y método, Sígueme, Salamanca, España 1977.

GARFINKEL, H. Studies in Ethnomethodology, Prentice-Hall, Englewood Cliffs, EE.UU. 1967.

GEERTZ, C. Los usos de la diversidad, Paidós, Barcelona, España 1996.

GEERTZ, C. La interpretación de las culturas, Gedisa, Barcelona, España 2001.

HEIDEGGER, M. Ser y Tiempo, Trotta, Madrid, España 2003.

LIZARAZO A.D. Hermenéutica de las imágenes. Iconos, figuraciones, sueños, Siglo XXI, México 2004.

MARCUS, G., y D. Cushman. El surgimiento de la antropología posmoderna, Gedisa, México 1991.

RICOEUR, P. El conflicto de las interpretaciones, FCE, Buenos Aires, Argentina 2001.

VATTIMO, G. La secularización de la filosofía, Gedisa, Barcelona, España 1998. 